\title{
Benefits of mesenchymal stem cells after partial bladder outlet obstruction
}

\author{
Bader Al-Saikan, MD; Jie Ding, MD; Edward Tredget, MD; Peter Metcalfe, MD
}

Department of Surgery, University of Alberta, Edmonton, AB, Canada

Cite as: Can Urol Assoc J 2016;10(1-2):El-6. http://dx.doi.org/10.5489/cuai.3257

Published online January 14, 2016.

\section{Abstract}

Introduction: Partial bladder outlet obstruction (pBOO) results in significant morbidity and mortality in the pediatric and adult populations. Mesenchymal stem cells (MSC) have been widely studied in many organ systems for the treatment and prevention of fibrotic and inflammatory conditions. Therefore, we hypothesize that systemic administration of MSC will demonstrate short-term biochemical, histological, and urodynamic benefits in an animal model for $\mathrm{pBOO}$.

Methods: After University ethics approval, $5 \times 106$ green fluorescent protein GFP-labeled MSC were intravenously injected concurrently with $\mathrm{pBOO}$ in adult Sprague-Dawley rats. Five groups $(\mathrm{n}=3$ / group) were analyzed: a) unobstructed controls; b) pBOO for seven days with intravenous MSC (7d+MSC); c) pBOO for seven days without intravenous MSC ( $7 d-M S C)$; d) pBOO for 14 days with intravenous MSC (14d+MSC), e) pBOO for 14 days without MSC (14d-MSC). Urodynamics were performed at the end of the experimental period and bladders were weighed. Immunohistochemistry was performed for GFP detection and reverse transcription polymerase chain reaction (RT-PCR) to detect mRNA of: TGF-B, HIF-1a, RhoA, GRP-78, lumican, and decorin.

Results: All animals remained healthy. GFP was detected in all treatment groups. MSC treatment resulted in a significant decrease in bladder capacity (0.91 cc vs. $2.15 \mathrm{cc}, \mathrm{p}=0.04)$. Treatment also resulted in significant decreases in mRNA levels of: TGF-B, HIF-1a, Rho-A, and GRP-78.

Conclusions: Systemic treatment with MSC was well tolerated and resulted in MSC accumulation after pBOO. Despite our low numbers, we were able to successfully demonstrate short-term urodynamic improvements and widespread, significant decreases in inflammatory mediators. We believe that this decreased inflammatory cascade will help prevent long-term detrusor deterioration.

\section{Introduction}

Partial bladder outlet obstruction (pBOO) is a ubiquitous problem in urology and can result in significant morbidity and mortality. We have previously demonstrated, in an animal model, that an acute $\mathrm{pBOO}$ will result in a progressive deterioration in bladder function. High intravesical pressure will induce significant inflammation, followed by smooth muscle cell (SMC) hypertrophy and, finally, can progress to a fibrotic, non-compliant, hostile bladder. ${ }^{1}$ We believe this can be correlated to both the long-term bladder deterioration seen in spinal dysraphism and posterior urethral valves. It can also be related to bladder decompensation secondary to prostatic hypertrophy.

Mechanical strain, bladder wall hypoxia, oxidative stress, and inflammation have all been implemented in the pathogenesis of $\mathrm{pBOO} .^{1,2}$ Several mediators and pathways are induced in response to $\mathrm{pBOO}$, including TGF $\beta$, RhoA, HIF1 $\alpha$, and GRP 78. ${ }^{1,3,4}$ Despite the volumes of knowledge gained in this field, however, contemporary clinical practice is limited to crude measures designed to minimize bladder distension and intravesical pressure, with clean intermittent catheterization $(\mathrm{ClC})$ and anti-muscarinic medication. ${ }^{5}$ The morbidity of contemporary treatment is significant and efficacy moderate, at best. The most significant recent clinical progress has been the realization that earlier and more aggressive application of $\mathrm{CIC}$ and medication results in improved outcomes. This is consistent with our theory that the early initiation of an aggressive regimen will minimize increases in pressure, decrease long-term physiologic stress, and prevent long-term decompensation. However, we feel that a more complete understanding of the pathophysiology, and its subsequent inhibition, will provide clinicians with vastly improved means of preventing bladder deterioration, improve continence and quality of life, and decrease need for morbid interventions, such as bladder augmentation and incontinent urinary diversions.

Mesenchymal stem cells (MSC) have been thoroughly investigated for their therapeutic and reparative potentials invivo, in-vitro, and in clinical trials. ${ }^{6-8}$ Their primary mechanisms of action are either via repopulation and reconstitution of diseased tissue or by a paracrine modulation of inflammatory cytokines. ${ }^{9}$ They have been shown to exert an inhibitory effect on many markers, including TGF $\beta$, IFN $\alpha / \gamma$, and TNF $\alpha .{ }^{9,10}$ 
We believe that this immunomodulation can provide a powerful tool in the prevention of damage secondary to $\mathrm{pBOO}$. Therefore, we hypothesize that acute systemic administration of MSCs after $\mathrm{pBOO}$ in our model will result in a decreased inflammatory response and improved shortterm urodynamic parameters.

\section{Methods}

Approval from the University of Alberta Animal Care and Use Committee was obtained. Fifteen female, adult SpragueDawley rats (weight $>200$ g) were divided into five groups $(n=3 /$ group). Three animals were unobstructed controls, and $\mathrm{pBOO}$ was induced surgically for seven and 14 days, with (treatment group) and without (control group) intravenous administration of GFP-producing MSCs. As previously described, ${ }^{11}$ an 18-guage angiocatheter was introduced via cystotomy and advanced into the urethra for calibration. A 2-0 silk suture was ligated around the urethra for the partial obstruction. After the designated experimental period, urodynamics were performed via suprapubic cystotomy with saline infused at $0.1 \mathrm{ml} /$ minute. Pressure was monitored until urinary leakage was observed per urethra. Total volume until leakage was recorded as bladder capacity and the pressure at time of leakage was recorded as "end-filling pressure." Bladders were excised, drained, and weighed.

Commercially obtained Sprague-Dawley MSCs (Cyagen Biosciences Inc, Sunnyvale, CA), transfected with a lentiviral encoded GFP expression, were acquired in passage 3, and cultured up to passage 8 using recommended growth medium and protocol (GUXMX-90011). A dose of $5 \times 106$ cells suspended in $0.5 \mathrm{ml}$ saline was administered intravenously (tail vein) at time of $\mathrm{pBOO}$ to treatment group animals. Dosing was based on similar published manuscripts. ${ }^{12,13}$

Sections of bladder tissue were fixed in $4 \%$ paraformaldehyde. Paraffin blocks were prepared with xylene and alcohol, washed with phosphate-buffered saline (PBS), and mounted using 4-feet 6-diamidino-2-phenylindole (DAPI) containing mounting-solution (ProLong Gold Antifade mounting medium, Invitrogen, ON, Canada). Images were captured using DAPI and FITC fluorescence filters (Carl Ziess Microimaging Inc., Thornwood, NY). Snap frozen tissue was homogenized with a micro-dismembrator, suspended in trizole solution, and total RNA was extracted using RNeasy spin columns (Qiagen, Mississauga, ON, Canada). DNAse digestion occurred for 60 minutes, and random primers used to synthesize first cDNA strand (Sigma, Oakville, ON, Canada). RT-PCR was performed (Power SYBR Green PCR Master Mix, $\mathrm{ABI}$, Foster City, CA) using $1 \mu \mathrm{L}$ of first strand product and $25 \mu \mathrm{L}$ of $0.2 \mu \mathrm{M}$ of target genes with upstream and downstream primers. An ABI 7300 real-time system (Applied Biosystems, Foster City, CA) was used for amplification. Hypoxanthine-guanine phosphoribosyl transferase (HPRT) amplification was used for standardization of amplification curves. Table 1 outlines forward and reverse primers sequences of genes used in this study. Glyceraldehyde-3phosphate dehydrogenase (GAPDH) was used as a reference gene and all experiments were performed in triplicate. Data are presented as mean \pm standard error. Analysis of variance (ANOVA) was performed for all data (STATA software Version 12.1), and $p \leq 0.05$ was used for statistical significance.

\section{Results}

All animals remained healthy for the duration of the experiments. GFP-positive cells were detected in all bladders after seven and 14 days of pBOO (Fig. 1). Partial obstruction significantly increased mean bladder weight after 14 days compared to unobstructed controls (535.0 \pm 82.5 vs. $200.7 \pm 4.6 \mathrm{mg}, \mathrm{p}<0.05)$. However, no difference was detected between untreated $\mathrm{pBOO}$ and MSC $\mathrm{pBOO}$ groups.

By 14 days, pBOO animals demonstrated a statistically significant increase in TGF $\beta$ in untreated animals compared to the unobstructed controls (mean fold change 3.40 \pm 0.30 , $\mathrm{p}<0.01)$. MSC treatment resulted in lower TGF $\beta$ levels after 14 days, but this only approached statistical significance (2.10 \pm 0.38 vs. $3.40 \pm 0.30, p=0.059)$ (Fig. 2a).

HIF1 $\alpha$ mRNA expression was significantly lower after seven days in the untreated $\mathrm{pBOO}$ compared to unobstructed controls $(0.15 \pm 0.03$-fold, $p=0.02)$, and was significantly higher than unobstructed controls at 14 days $(4.39 \pm 0.98-$ fold, $\mathrm{p}=0.03$ ). MSC-treated $\mathrm{pBOO}$ animals had significantly lower HIF1 $\alpha$ than untreated pBOO animals $(0.37 \pm 0.18$ vs. $4.39 \pm 0.98$ fold, $p=0.02$ ) (Fig. 2b).

RhoA mRNA was increased after 14 days of $\mathrm{pBOO}$ (1.92 \pm 0.16 -fold, $p=0.04)$ and treatment with MSC resulted in a significant decrease $(0.45 \pm 0.23$ vs. $1.92 \pm 0.16$-fold, $p<0.05)$ (Fig. 2c). GRP78 was also significantly lower in the $\mathrm{pBOO}$

\section{Table 1. List of PCR primers sequences}

\begin{tabular}{lcc}
\hline Gene & Forward sequence & Reverse sequence \\
\hline GRP78 & $5^{\prime}$-CCAGCTTACTTCAATGATGCAC-3' & 5'-CTTCTCTCCCTCTCTCTTATCC-3' $^{\prime}$ \\
RhoA & $5^{\prime}$-AGGACCAGTTCCCAGAGGTT-3' & 5'-ACTATCAGGGCTGTCGATGG-3' $^{\prime}$ \\
TGF $\beta 1$ & $5^{\prime}$-GAGGTGACCTGGGCACCAT-3' & $5^{\prime}$-GGCCATGAGGAGCAGGAA-3' \\
HIF1 $\alpha$ & $5^{\prime}$-TGCTTGGTGCTGATTTGTGA-3' & $5^{\prime}$-GGTCAGATGATCAGAGTCCA-3' \\
\hline
\end{tabular}




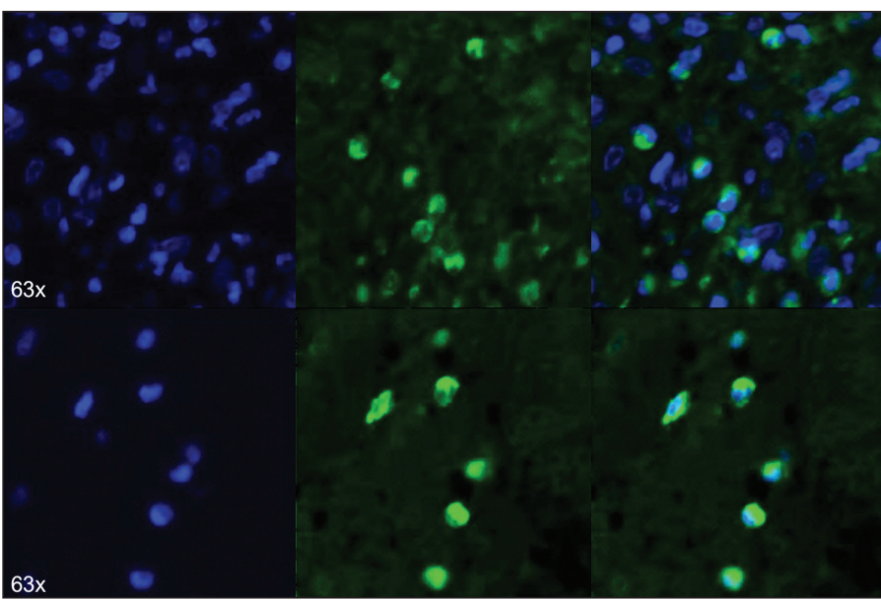

Fig. 1. Fluorescence microscopy images from two representative animals showing GFP-expressing MSCs throughout bladder tissue of 14 days pBO0+MSC group.

animals treated with MSC compared to untreated $\mathrm{pBOO}$ after 14 days $(0.83 \pm 0.12$ vs. $2.57 \pm 0.61, p<0.05)$ (Fig. $2 d$ ).

Although bladder pressures increased after pBOO, these were not significantly higher than the unobstructed animals and no change was detected with MSC treatment (Fig. 3a). However, pBOO did increase bladder capacity after 14 days when compared with unobstructed controls $(2.15 \pm 0.30$ vs. $0.90 \pm 0.17 \mathrm{ml}, \mathrm{p}=0.02)$, and treatment with MSC eliminated this effect $(0.91 \pm 0.29$ vs. $2.15 \pm 0.3 \mathrm{ml}, \mathrm{p}<0.05)$ (Fig. $3 b)$.

\section{Discussion}

Treatment with MSC has demonstrated exciting results in many pathologic conditions and we believe our data shows similar promise with respect to pBOO. ${ }^{14,15} \mathrm{MSC}$ possess significant immunomodulatory effects, promote tissue healing and regeneration, prevent apoptosis, and are pro-angiogenic. ${ }^{14,16}$ They have been shown to inhibit many inflammatory markers, including TNF $\alpha$, IFN $\alpha / \gamma, \operatorname{TGF} \beta$, and secrete anti-inflammatory cytokines, including IL-10.9,10 In a lung injury model, MSCs reduced TGF $\beta$, IFN $\gamma$, and TNF $\alpha .{ }^{9}$ After a murine myocardial infarction, injection of MSCs resulted in improved left ventricular function. ${ }^{17}$ In the urinary bladder, MSCs improved compliance after four weeks of pBOO. ${ }^{15}$

We have previously described the inflammatory reaction that occurs after a surgically induced $\mathrm{pBOO}$. We hypothesized that concomitant administration of MSC with $\mathrm{pBOO}$ will result in a decrease in these inflammatory mediators and that this will result in improvement of several quantifiable parameters.

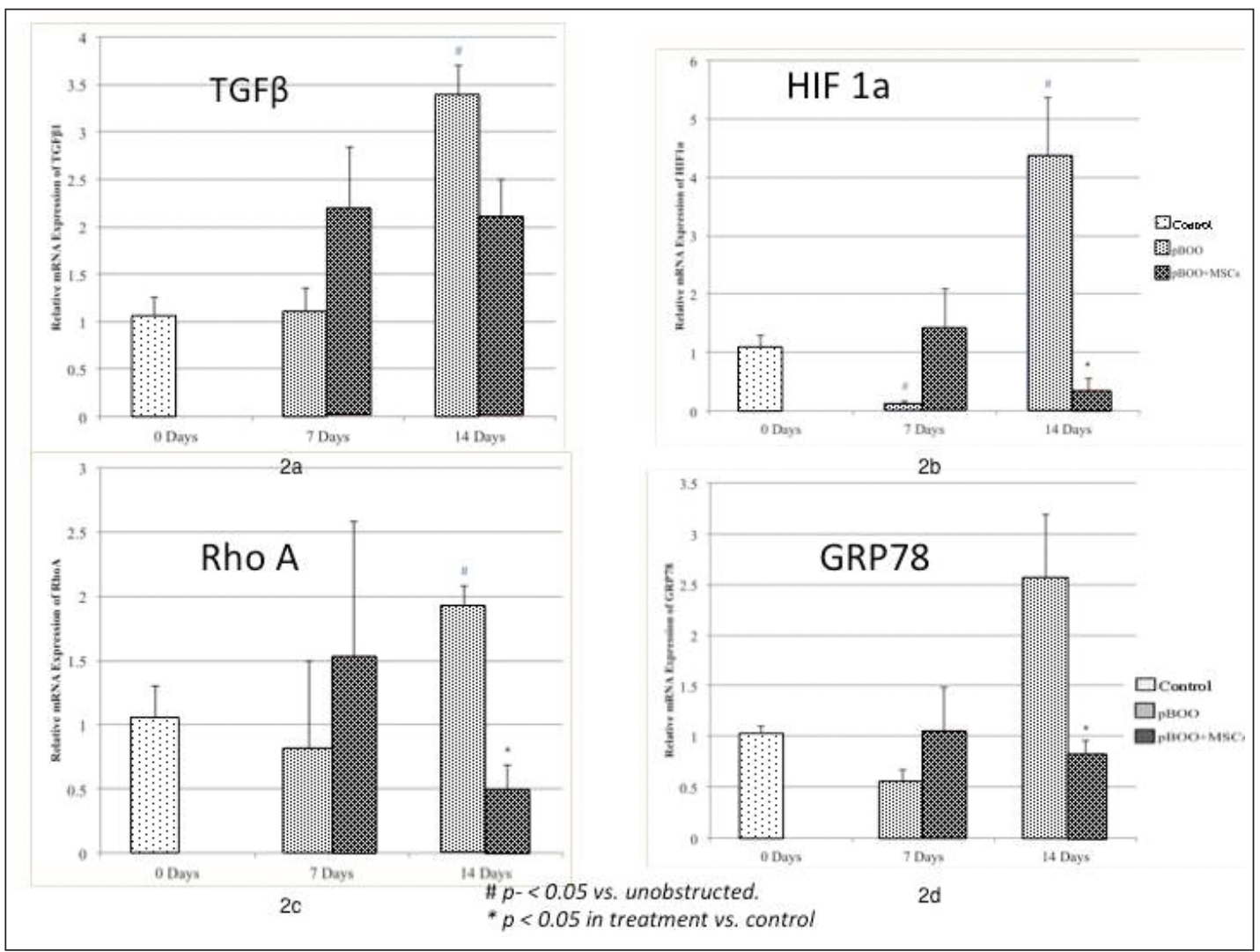

Fig. 2. RT-PCR results in controls and after pBO0 for 7 and 14 days; 2a) TGF-B levels increased significantly after 14 days, but the decrease with MSC treatment was not statistically significant; 2b) HIF-1a; 2c) RhoA; and 2d) GRP78 levels increase significantly after 14 days pBO0 and treatment with MSC results in a statistically significant reduction in levels. 


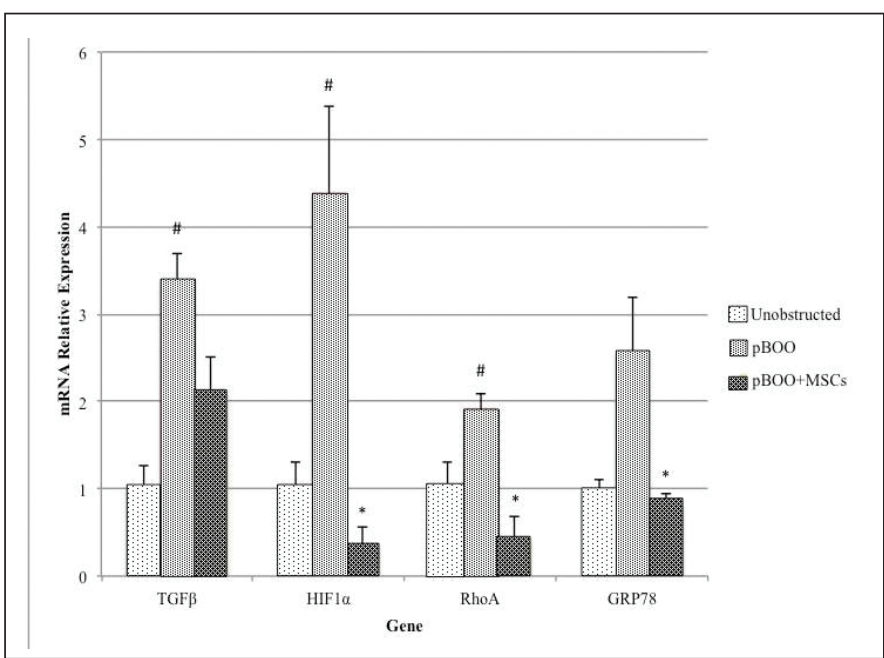

Fig. 3a. Summary graph of the 4 mediators examined after 14 days pB00. This demonstrates the upregulation compared to controls and decrease with MSC administration.

Our experiment definitively demonstrated uptake of MSC into bladders after pBOO. However, we were not able to examine uptake into other organs to discern whether the MSC accumulation was a passive process or if the inflammation resulted in active recruitment of our cells. Notwithstanding this, the accumulation was associated with a marked reduction in several important cytokines, all previously demonstrated to be actively involved in the pathophysiology of pBOO.
TGF $\beta$ is increased in many inflammatory states, is a major factor in inflammation and fibrosis, and has many downstream mediators, including: fibronectin, small leucine rich proteoglycans, and collagen fibril production. ${ }^{18}$ Human bladder cells treated with TGF $\beta$ result in muscle hypertrophy and collagen deposition, ${ }^{19}$ while TGF $\beta$ type 2 receptor knockout mice had less SMC hypertrophy and fibrosis. ${ }^{20}$ Therefore, decreased levels of TGF $\beta$ may be a fundamental step in preventing the progression to fibrosis.

Bladder wall hypoxia is significant after $\mathrm{pBOO}, 1,15$ and we demonstrated that

MSCs were able to reduce HIF1 $\alpha$ levels after 14 days. This may be due to a broad anti-inflammatory effect or secondary to the secretion of vascular endothelial growth factor (VEGF) and basic fibroblast growth factor (BFGF) by the MSC, which are involved in inducing angiogenesis, although our experiment is likely too acute to result in increased blood vessel density. 21,22

Mechanical strain and hypoxia are known to activate the RhoA/ROCK pathway in many studies ${ }^{23,24}$ and our MSCtreated animals exhibited significantly lower RhoA mRNA expression after 14 days of pBOO. RhoA increases bladder contractility and interferes with endothelial nitric oxide synthase (eNOS) in the vascular endothelium, urther worsening hypoxia. ${ }^{25}$ Therefore, inhibition of this pathway may have a long-term benefit of decreased contractility, intravesical pressures, and hypoxia.

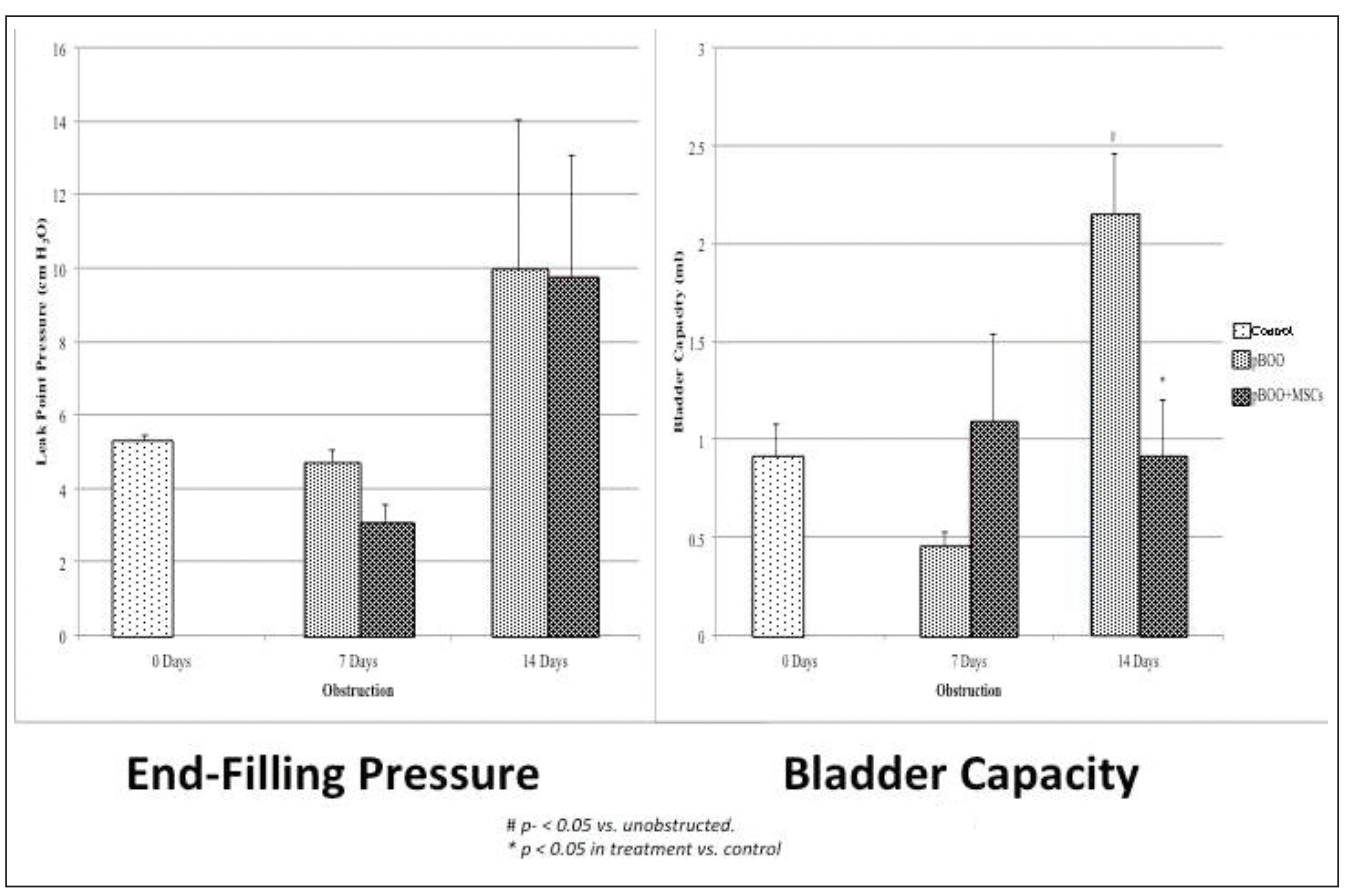

Fig. 3b. Urodynamic results. (Left) End-filling pressure for each time course of the experiment in control and treatment groups. There was not a statistically significant rise in bladder pressure over the 14 days of $p B 00$, nor did administration of MSC affect results; (Right) Bladder capacity increased significantly over controls after 14 days of pB00. Treatment with MSC significantly reduced capacity, so it was again not different from non-obstructed controls. 
Increased GRP78 is a marker of intracellular and endoplasmic reticulum stress (ERS). It is a molecular chaperon in the endoplasmic reticulum (ER), which is involved in protein folding. ${ }^{26}$ Cellular stress induces an accumulation of improperly folded proteins in the lumen of the $E R$, which causes apoptosis. ${ }^{26,27}$ In this experiment, GRP78 mRNA is increased after 14 days of pBOO and treatment with MSCs resulted in normalized levels. This reduction in GRP78 implies that MSCs have reduced the degree of intracellular stress, which may result in a normalization of tissue functioning and decreased apoptosis. However, the finding of greatest clinical relevance was the improvement in bladder capacity. As per our previous experiments, the first urodynamic change expected after pBOO is an increase in capacity. ${ }^{1}$ We feel this may be analogous to the clinical deterioration seen in posterior urethral valve patients who acquire increased post-void residuals before developing elevated bladder pressures, hydronephrosis, and renal failure with the "valve bladder syndrome." ${ }^{28}$ The increasing capacity eventually reaches its viscoelastic limitations, and bladder pressure subsequently increases.

Although our results show great promise, with their physiologic and clinical relevance, further work needs to be done to determine the long-term benefits after acute administration of MSC. Will the mitigation of the inflammatory cascade result in truly significant, clinically relevant improvement in bladder function? The most relevant experiments will involve the administration of MSC after chronic damage has occurred following $\mathrm{pBOO}$, which is much more pertinent to contemporary clinical scenarios.

Despite the small numbers of animals in each group, we were able to demonstrate a significant effect. We were bound by our animal protocol to ensure that the lowest numbers possible are used. Furthermore, given the acute nature of the experiments, we found far less variability in our urodynamics and did not feel that further repetition was necessary. We intentionally studied the very acute effects, as this would ensure the results are secondary to the paracrine modulation of the inflammatory cascade, not a repopulation or regenerative role. We look forward to future experiments whereby we will be able to examine longer-term outcomes and also the effect of administration after bladder deterioration has occurred.

\section{Conclusion}

Intravenous administration of MSC at the time of an acute, surgically controlled $\mathrm{pBOO}$ resulted in a significant reduction in multiple cytokines, which have been previously implicated in the pathophysiology of pBOO. Furthermore, we demonstrated urodynamic effects that confirm a decreased stress on the bladder and prove functional, clinically relevant improvements. Therefore, we feel this lays important groundwork for further exploration of the potential role for MSC in the prevention and treatment of bladder decompensation after $\mathrm{pBOO}$.

Competing interests: Dr. Al-Saikan, Dr. Ding, and Dr. Metcalfe declare no competing financial or personal interests. Dr. Tredget is or has been an Advisory Board member for ScarX Therapeutics and has received grant/honoraria from Klox Technologies.

Acknowldgement: This research was funded by Northern Alberta Urology Foundation, Edmonton Civic Employees Union, and Royal Embassy of Saudi Arabia

This paper has been peer-reviewed.

\section{References}

1. Metcalfe PD, Wang J, Jiao $\mathrm{H}$, et al. Bladder outlet obstruction: Progression from inflammation to fibrosis. BJU Int 2010;106:1686-94. http://dx.doi.org/10.1111/i.1464-410X.2010.09445.x

2. Yuan $X$, Yuan $X$, Wu S, et al. Role of nitric oxide synthase in bladder pathologic remodeling and dysfunction resulting from partial outlet obstruction. Urology 2011;77:El-8. http://dx.doi.org/10.1016/i. urology.2010.11.018

3. Boberg L, Boberg L, Poljakovic $M$, et al. Role of Rho-kinase and protein kinase C during contraction of hypertrophic detrusor in mice with partial urinary bladder outlet obstruction. BJU Int 2012;109:132-40. http://dx.doi.org/10.1111/j.1464-410X.2011.10435.x

4. Sawada N, Sawada N, Yao J, et al. Involvement of hypoxia-triggered endoplasmic reticulum stress in outlet obstruction-induced apoptosis in the urinary bladder. Lab Invest 2008;88:553-63. http://dx.doi. org/10.1038/labinvest.2008.21

5. Moisey CU, Moisey CU, Stephenson TP, et al. The urodynamic and subjective results of treatment of detrusor instability with oxybutynin chloride. Br J Urol 1980;52:472-5. http://dx.doi.org/10.1111/i.1464410X.1980.tb03093.x

6. Ortiz LA, Gambelli F, McBride C, et al. Mesenchymal stem cell engraftment in lung is enhanced in response to bleomycin exposure and ameliorates its fibrotic effects. PNAS 2003:1-5. http://dx.doi. org/10.1073/pnas. 1432929100

7. Williams AR, Suncion VY, McCall F, et al. Durable scar size reduction due to allogeneic mesenchymal stem cell therapy regulates whole-chamber remodeling. J Am Heart Assoc 2013;2:e000140. http:// dx.doi.org/10.1161/JAHA.113.000140

8. Reinders MEJ, Reinders MEJ, de Fijter JW, et al. Autologous bone marrow-derived mesenchymal stromal cells for the treatment of allograft rejection after renal transplantation: Results of a phase I study. Stem Cells Transl Med 2013;2:107-11. http://dx.doi.org/10.5966/sctm.2012-0114

9. Moodley Y, Atienza D, Manuelpillai U, et al. Human umbilical cord mesenchymal stem cells reduce fibrosis of bleomycin-induced lung injury. Am J Pathol 2009;175:303-13. http://dx.doi.org/10.2353/ aipath.2009.080629

10. Caplan Al. Adult mesenchymal stem cells for tissue engineering versus regenerative medicine. J Cell Physiol 2007;213:341-7. http://dx.doi.org/10.1002/icp.21200

11. Sutherland RS, Sutherland RS, Baskin $L S$, et al. Neuroanatomical changes in the rat bladder after bladder outlet obstruction. Br J Urol 1998;82:895-901. http://dx.doi.org/10.1046/i.1464410X.1998.00873.x

12. Asanuma $\mathrm{H}$, Asanuma $\mathrm{H}$, Vanderbrink $B A$, et al. Arterially delivered mesenchymal stem cells prevent obstruction-induced renal fibrosis. J Surg Res 2011;168:e51-9. http://dx.doi.org/10.1016/i. iss.2010.06.022

13. Villanueva $S$, Villanueva $S$, Ewertz $E$, et al. Mesenchymal stem cell injection ameliorates chronic renal failure in a rat model. Clin Sci 2011;121:489-99. http://dx.doi.org/10.1042/CS20110108

14. Abdel Aziz MT, Abdel Aziz MT, Atta HM, et al. Therapeutic potential of bone marrow-derived mesenchymal stem cells on experimental liver fibrosis. Clin Biochem 2007;40:893-9. http://dx.doi.org/10.1016/i. clinbiochem.2007.04.017

15. Woo LL, Woo LL, Tanaka ST, et al. Mesenchymal stem cell recruitment and improved bladder function after bladder outlet obstruction: Preliminary data. JURO 2011;185:1132-8. http://dx.doi.org/10.1016/i. juro.2010.10.033 
Al-Saikan et al.

16. Zhao D-C, Zhao D-C, Lei J-X, et al. Bone marrow-derived mesenchymal stem cells protect against experimental liver fibrosis in rats. World J Gastroenterol 2005;11:3431-40. http://dx.doi.org/10.3748/ wig.v1 1.i22.3431

17. Dai W, Dai W, Hale SL, et al. Allogeneic mesenchymal stem cell transplantation in postinfarcted rat myocardium: short- and long-term effects. Circulation 2005;112:214-23. http://dx.doi.org/10.1161/ CIRCULATIONAHA.104.527937

18. Sharma K, Sharma K, Ziyadeh FN, et al. The emerging role of transforming growth factor-beta in kidney diseases. Am J Physiol 1994;266:F829-42.

19. Howard P, Kucich U, Coplen D. Transforming growth factor-beta l-induced hypertrophy and matrix expression in human bladder smooth muscle cells. Urology 2005;66:1349-53. http://dx.doi.org/10.1016/i. urology.2005.06.124

20. Anumanthan $G$, Anumanthan $G$, Tanaka $S T$, et al. Bladder stromal loss of transforming growth factor receptor II decreases fibrosis after bladder obstruction. JURO 2009;182:1775-80. http://dx.doi. org/10.1016/i.juro.2009.05.126

21. Kinnaird T, Kinnaird T, Stabile E, et al. Local delivery of marrow-derived stromal cells augments collateral perfusion through paracrine mechanisms. Circulation 2004;109:1543-9. http://dx.doi.org/10.1161/01. CIR.0000124062.31102.57

22. Weil BR, Weil BR, Markel TA, et al. Mesenchymal stem cells enhance the viability and proliferation of human fetal intestinal epithelial cells following hypoxic injury via paracrine mechanisms. Surgery 2009;146:190-7. http://dx.doi.org/10.1016/i.surg.2009.03.031
23. Wang Z, Wang Z, Jin N, et al. Rho-kinase activation is involved in hypoxia-induced pulmonary vasoconstriction. Am J Respir Cell Mol Biol 2001;25:628-35. http://dx.doi.org/10.1165/aircmb.25.5.4461

24. Schiffrin EL, Schiffrin EL, Touyz RM, et al. From bedside to bench to bedside: Role of renin-angiotensinaldosterone system in remodeling of resistance arteries in hypertension. Am J Physiol Heart Circ Physiol 2004;287:H435-46. http://dx.doi.org/10.1152/aipheart.00262.2004

25. Ming X-F, Ming X-F, Viswambharan H, et al. Rho GTPase/Rho kinase negatively regulates endothelial nitric oxide synthase phosphorylation through the inhibition of protein kinase B/Akt in human endothelial cells. Mol Cell Biol 2002;22:8467-77. http://dx.doi.org/10.1128/MCB.22.24.8467-8477.2002

26. Brooks DA, Brooks DA. Introduction: Molecular chaperones of the ER: Their role in protein folding and genetic disease. Semin Cell Dev Biol 1999;10:441-2. http://dx.doi.org/10.1006/scdb.1999.0314

27. $X \cup C, X \cup C$, Bailly-Maitre B, et al. Endoplasmic reticulum stress: Cell life and death decisions. J Clin Invest 2005;115:2656-64. http://dx.doi.org/10.1172/JCI26373

28. Smith GH, Canning DA, Schulman SL, et al. The long-term outcome of posterior urethral valves treated with primary valve ablation and observation. JURO 1996;155:1730-4.

Correspondence: Dr. Peter Metcalfe, Department of Surgery, University of Alberta, Edmonton, AB; pmetcalf@ualberta.ca 